\title{
Diffusivity of $\mathrm{Al}$ and $\mathrm{Fe}$ near the diffusion bonding interface of $\mathrm{Fe}_{3} \mathrm{Al}$ with low carbon steel
}

\author{
LI YAJIANG* $*^{\dagger}$, WANG JUAN ${ }^{\dagger}$, YIN YANSHENG ${ }^{\dagger}$ and MA HAIJUN ${ }^{\dagger}$ \\ *Key Lab of Liquid Structure and Heredity of Materials, Ministry of Education, Shandong University, Jinan 250061, China \\ ${ }^{\dagger}$ National Key Lab of Advanced Welding Technology, Harbin Institute of Technology, Harbin 150001, China
}

MS received 20 September 2004

\begin{abstract}
The distribution of elements near the $\mathrm{Fe}_{3} \mathrm{Al} / \mathrm{Q} 235$ diffusion bonding interface was computed by the diffusion equation as well as measured by means of EPMA. The results indicated close agreement between the two for iron and aluminium. Diffusion coefficient in the interface transition zone is larger than that in the $\mathrm{Fe}_{3} \mathrm{Al}$ and Q235 steel at the same temperature, which is favourable to elemental diffusion. The diffusion distance near the $\mathrm{Fe}_{3} \mathrm{Al} / \mathrm{Q} 235$ interface increased with increasing heating temperature, $T$, and the holding time, $t$. The relation between the width of the interface transition zone, $x$, and the holding time, $t$, conformed to parabolic growth law: $x^{2}=4.8 \times 10^{4} \exp (-133 / R T)\left(t-t_{0}\right)$. The width of the interface transition zone does not increase significantly for holding times beyond $60 \mathrm{~min}$.
\end{abstract}

Keywords. $\mathrm{Fe}_{3} \mathrm{Al}$; intermetallic; diffusion bonding; interface; diffusion.

\section{Introduction}

$\mathrm{Fe}_{3} \mathrm{Al}$ intermetallic has high resistance to high temperature, abrasion and corrosion. It is likely to be a new high temperature structural material and has attracted close attention of many researchers (David et al 1989, 1993; Mckamey et al 1991). It has wide prospects in application if $\mathrm{Fe}_{3} \mathrm{Al}$ and carbon steel could be welded firmly by advanced diffusion bonding technology. The full diffusion of elements near the interface is critical to realize diffusion bonding of the dissimilar materials. In recent years, researchers have made some studies on elemental diffusion behaviour during bonding and have set theoretical model for diffusion bonding (Derby et al 1982). On the basis of the model, elemental diffusion equation near the TiAl/40Cr diffusion bonding interface has been set (He et al 2002). But up to now, atom diffusion behaviour near the $\mathrm{Fe}_{3} \mathrm{Al} / \mathrm{Q} 235$ interface is not reported.

The element diffusion coefficient in the interface transition zone is a dynamic value during diffusion bonding. Different microstructures in the interface transition zone for $\mathrm{Fe}_{3} \mathrm{Al} / \mathrm{Q} 235$ dissimilar materials are formed because of the difference in element concentration. In the present paper, based on Fick's second Law related to non-steady state diffusion, the interface initial and boundary conditions are determined to study the element diffusion behaviour near the $\mathrm{Fe}_{3} \mathrm{Al} / \mathrm{Q} 235$ interface by numerical analysis method. The computed result is compared with the element distribution measured by means of EPMA to understand the effect of technology parameters. The paper

*Author for correspondence (yajli@sdu.edu.cn) provides theoretical and experimental basis for studying diffusion behaviour near the interface.

\section{Method}

The materials used in the test are $\mathrm{Fe}_{3} \mathrm{Al}$ intermetallic and Q235 low carbon steel. $\mathrm{Fe}_{3} \mathrm{Al}$ was melted by the vacuum induction furnace and then fabricated into plate by the hot rolled technology, whose chemical compositions and the properties are shown in table 1 . The chemical compositions and the properties of Q235 steel are (\%): C 0.17, Mn 0.48, Si 0.28, S 0.018, P 0.020, yield strength, $225 \mathrm{MPa}$, elongation, $20 \%$.

A mathematical model of element diffusion is set up for the case of diffusion bonding. A program is formulated to calculate the element distribution near the $\mathrm{Fe}_{3} \mathrm{Al} /$ Q235 interface. The $\mathrm{Fe}_{3} \mathrm{Al} / \mathrm{Q} 235$ diffusion joints are obtained by vacuum diffusion bonding employing different technological parameters. Some specimens, including $\mathrm{Fe}_{3} \mathrm{Al} /$ Q235 diffusion interface, are cut out by means of a linecutting machine for metallographic observation. The distribution of $\mathrm{Al}$ and $\mathrm{Fe}$ near $\mathrm{Fe}_{3} \mathrm{Al} / \mathrm{Q} 235$ interface is measured by means of EPMA. The calculated value is compared with the measured value to analyse the effect of technological parameters on element diffusion behaviour near the $\mathrm{Fe}_{3} \mathrm{Al} / \mathrm{Q} 235$ interface.

\section{Results and analysis}

3.1 Diffusion bonding technology of $\mathrm{Fe}_{3} \mathrm{Al} / \mathrm{Q} 235$ dissimilar materials

The $\mathrm{Fe}_{3} \mathrm{Al}$ and Q235 steel plate are overlapped to be joined by the vacuum diffusion bonding. Oxide film on the sur- 
face of workpiece is removed by mechanical and chemical methods. Workhorse-II vacuum diffusion bonding equipment is used with a heat power, $45 \mathrm{~kW}$. Other parameters of diffusion bonding are: temperature, $T=960$ $\sim 1080^{\circ} \mathrm{C}$, holding time, $t=15 \sim 60 \mathrm{~min}$, pressure, $P=10$ $\sim 17.5 \mathrm{MPa}$ and vacuum, $5 \times 10^{-4} \mathrm{~Pa}$. The assemblage and location of diffusion bonding samples in the vacuum chamber are shown in figure 1 .

A good diffusion interface cannot be formed if the heating temperature is too low, since extent of diffusion is not sufficient even though the holding time is longer and the pressure is larger. But if the heating temperature is too high, the grains will grow up seriously and the diffusion transition zone can become wider, which will adversely affect the performance of the diffusion bonding joint. The test results indicated that the heating temperature should not be lower than $1000^{\circ} \mathrm{C}$ in order to ensure the interface combination. A schematic of the relation- ship between different variables during the $\mathrm{Fe}_{3} \mathrm{Al} / \mathrm{Q} 235$ diffusion bonding is shown in figure 2 .

The diffusion of $\mathrm{Al}$ atom near the $\mathrm{Fe}_{3} \mathrm{Al} / \mathrm{Q} 235$ interface is determined by the heating temperature and holding time. When the holding time is short, the atoms do not have enough time to diffuse and the bonding is weak. Satisfactory $\mathrm{Fe}_{3} \mathrm{Al} / \mathrm{Q} 235$ diffusion bonding joint can be obtained even for a holding time of $30 \mathrm{~min}$ if the temperature, $T=1040^{\circ} \mathrm{C}$. But the grains become coarser if the holding time is too long. The test results indicated that the holding time should be $<60$ min to obtain an excellent diffusion bonding joint.

Since $\mathrm{Fe}_{3} \mathrm{Al}$ and Q235 steel differ greatly in physical performance, too large a pressure will lead to the deformation of $\mathrm{Fe}_{3} \mathrm{Al}$ base material. The test results indicated that the pressure should be $<17.5 \mathrm{MPa}$ during diffusion bonding of $\mathrm{Fe}_{3} \mathrm{Al} / \mathrm{Q} 235$ dissimilar materials in order to prevent the deformation of weldment.

Table 1. Chemical composition and thermo-physical properties of $\mathrm{Fe}_{3} \mathrm{Al}$ intermetallic.

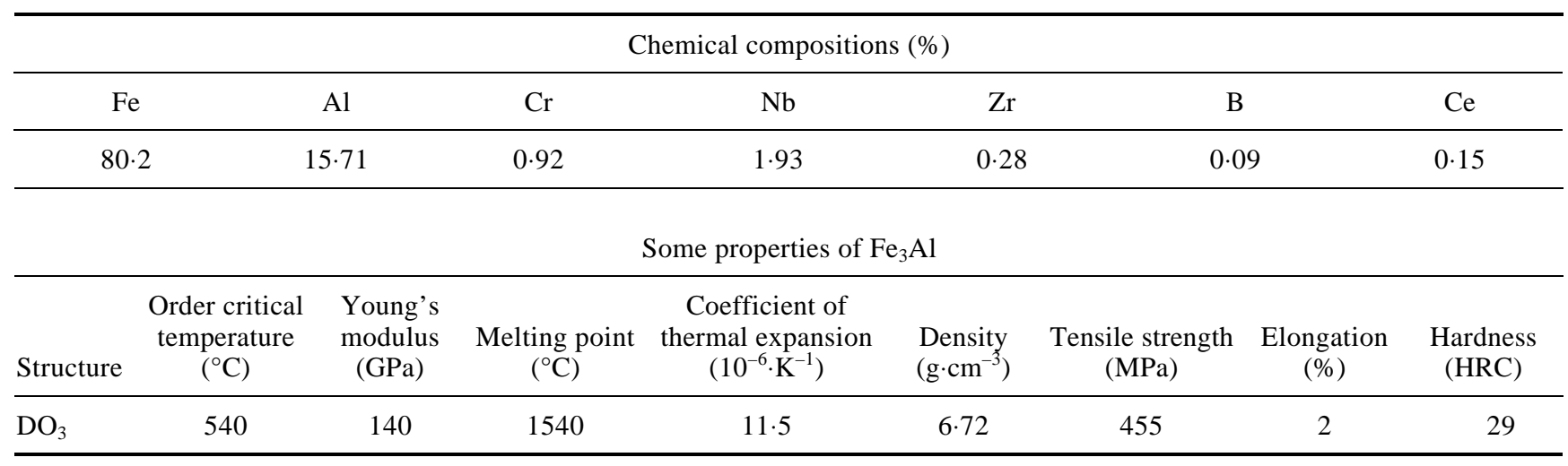

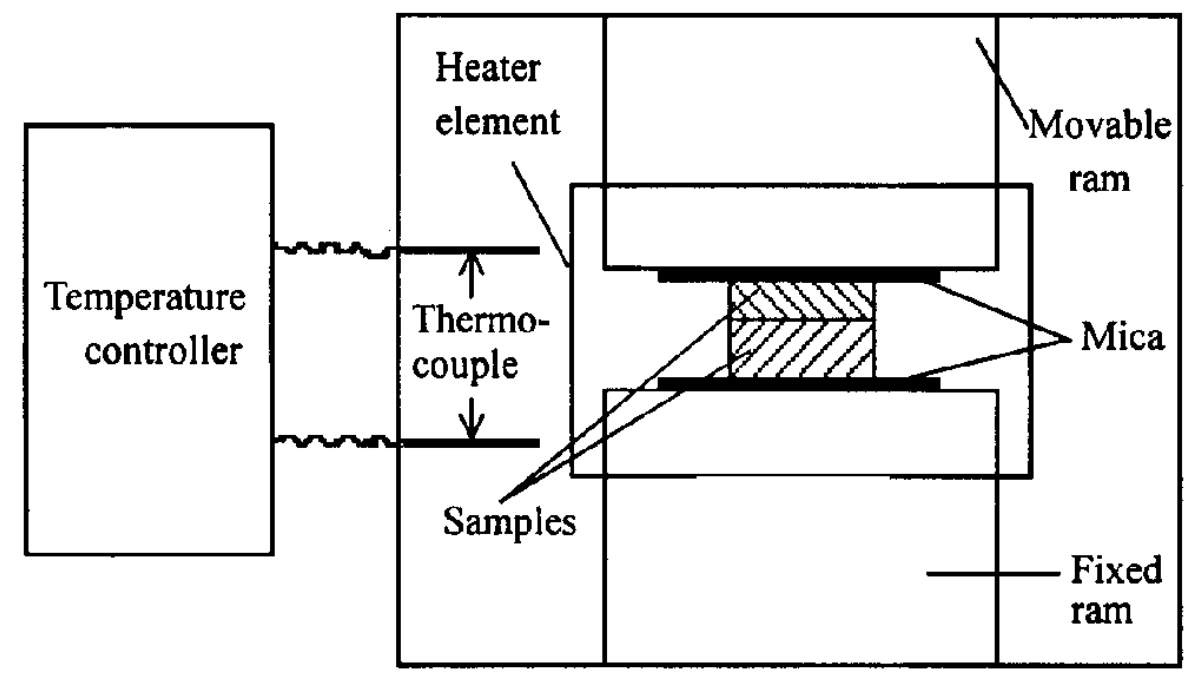

Figure 1. Assemblage and location of diffusion bonding samples in the vacuum chamber. 


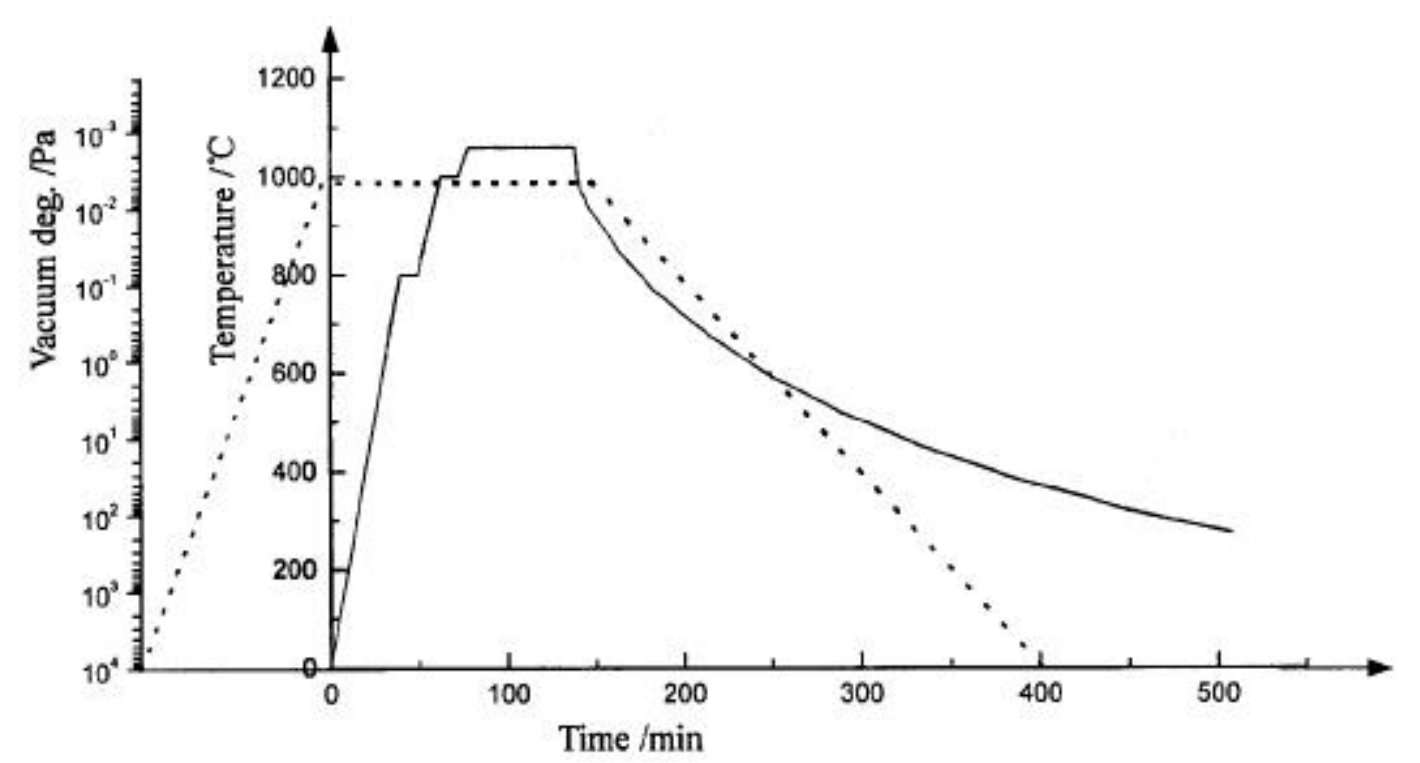

Figure 2. The technological parameter during the diffusion bonding of $\mathrm{Fe}_{3} \mathrm{Al} / \mathrm{Q} 235$ dissimilar materials.

Table 2. Diffusion factor $\left(D_{0}\right)$ and activity energy $(Q)$ of elements in $\mathrm{Fe}_{3} \mathrm{Al}$ and Q235 steel.

\begin{tabular}{lcccccc}
\hline & \multicolumn{2}{c}{$\mathrm{Fe}_{3} \mathrm{Al}$ alloy } & & \multicolumn{2}{c}{$\mathrm{Q} 235$ steel } \\
\cline { 2 - 3 } \cline { 6 - 6 } Parameters & $\mathrm{Al}$ & $\mathrm{Fe}$ & & $\mathrm{Al}$ & $\mathrm{Fe}$ \\
\hline$D_{0}\left(10^{6} \mu \mathrm{m}^{2} \cdot \mathrm{s}^{-1}\right)$ & $1 \cdot 7$ & 4 & & 170 & 200 \\
$Q\left(\mathrm{~kJ} \cdot \mathrm{mol}^{-1}\right)$ & $211 \cdot 1$ & $166 \cdot 4$ & & 142 & 239 \\
\hline
\end{tabular}

\subsection{Numerical analysis of diffusion of element near the interface}

The elements diffuse across $\mathrm{Fe}_{3} \mathrm{Al} / \mathrm{Q} 235$ interface which can be calculated by the diffusion equation. Suppose an element has an initial concentration in $\mathrm{Fe}_{3} \mathrm{Al}$ intermetallic and Q235 steel of $C_{1}$ and $C_{2}$, respectively, the element distribution near the $\mathrm{Fe}_{3} \mathrm{Al} / \mathrm{Q} 235$ interface obeys nonsteady state diffusion equation of Fick's second Law (Huang 1996):

$$
\frac{\partial C}{\partial t}=D \frac{\partial^{2} C}{\partial x^{2}}
$$

The element concentration equation near the $\mathrm{Fe}_{3} \mathrm{Al} / \mathrm{Q} 235$ interface is obtained according to the initial condition, $C(x, 0)=C_{1}(x<0), C_{2}(x>0)$; and boundary condition, $C(x, t)=C_{1}(x=-\infty), C_{2}(x=+\infty)$. Owing to the larger difference of element diffusion coefficient in the $\mathrm{Fe}_{3} \mathrm{Al}$ and Q235 steel, boundary condition is set up as

$$
D_{1} \frac{\partial C_{\mathrm{A}}(x=0, t)}{\partial x}=D_{2} \frac{\partial C_{\mathrm{B}}(x=0, t)}{\partial x} .
$$

The element concentration equation near the diffusion bonding interface is obtained as

$$
C(x, t)=\left\{\begin{aligned}
C_{\mathrm{A}}(x, t)= & \frac{C_{1}+C_{2}}{2}+\frac{\sqrt{D_{2}}\left(C_{1}-C_{2}\right)}{\sqrt{\pi}\left(\sqrt{D_{1}}+\sqrt{D_{2}}\right)} \\
& {\left[\int_{0}^{n_{1}} \exp \left(-\eta_{1}^{2}\right) \mathrm{d} \eta_{1}\right](x<0) } \\
C_{\mathrm{B}}(x, t)= & \frac{C_{1}+C_{2}}{2}+\frac{\sqrt{D_{1} D_{2}}\left(C_{1}-C_{2}\right)}{\sqrt{\pi}\left(D_{2}+\sqrt{D_{1} D_{2}}\right)} \\
& {\left[\int_{0}^{n_{2}} \exp \left(-\eta_{2}^{2}\right) \mathrm{d} \eta_{2}\right](x>0) . }
\end{aligned}\right.
$$

According to the error function,

$$
\operatorname{erf}(Z)=\frac{2}{\sqrt{\pi}} \int_{0}^{Z} \exp \left(-\eta^{2}\right) \mathrm{d} \eta,
$$

the error function solution of (3) is

$$
C(x, t)=\left\{\begin{aligned}
C_{\mathrm{A}}(x, t)= & \frac{C_{1}+C_{2}}{2}+\frac{\sqrt{D_{2}}\left(C_{1}-C_{2}\right)}{\sqrt{\pi}\left(\sqrt{D_{1}}+\sqrt{D_{2}}\right)} \\
& \operatorname{erf}\left(\frac{x}{4 D_{1} t}\right)(x<0) . \\
C_{\mathrm{B}}(x, t)= & \frac{C_{1}+C_{2}}{2}+\frac{\sqrt{D_{1} D_{2}}\left(C_{1}-C_{2}\right)}{\sqrt{\pi}\left(D_{2}+\sqrt{D_{1} D_{2}}\right)} \\
& \operatorname{erf}\left(\frac{x}{4 D_{2} t}\right)(x>0) .
\end{aligned}\right.
$$


Equation (4) is the relation between element concentration, diffusion distance, $x$, and holding time, $t$, near the $\mathrm{Fe}_{3} \mathrm{Al} / \mathrm{Q} 235$ interface. The most important parameter in the calculation is diffusion coefficient, $D$ (including diffusion factor, $D_{0}$ and activity energy, $Q$ ). The element concentration on two besides the interface was measured by means of EPMA. The element diffusion coefficient was calculated by diffusion factor, $D_{0}$ and activity energy, $Q$, measured by means of radioactive isotope tracer method. The values of $D_{0}$ and $Q$ of the elements in $\mathrm{Fe}_{3} \mathrm{Al}$ alloy and Q235 steel are shown in table 2.

According to the Arrhenius equation, $D=D_{0} \exp (-Q /$ $R T)$, the program is edited to calculate the diffusion coef-

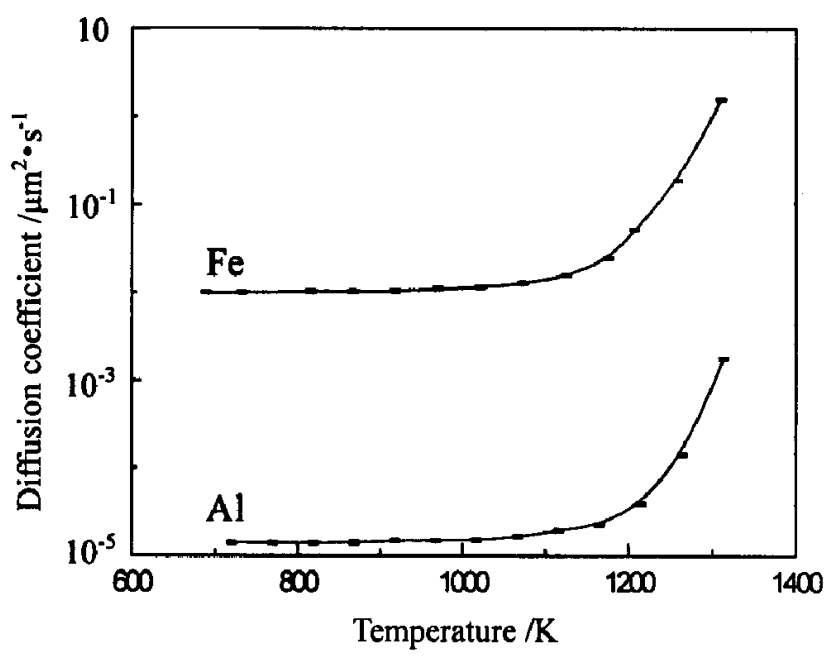

Figure 3. Variation of diffusion coefficient with temperature in $\mathrm{Fe}_{3} \mathrm{Al}$ alloy. ficient, $D$, of $\mathrm{Al}$, Fe elements at different temperatures in $\mathrm{Fe}_{3} \mathrm{Al}$ alloy, and the results are shown in figure 3 .

For a heating temperature, $T=1060^{\circ} \mathrm{C}$ and holding time, $t=45 \mathrm{~min}$, concentration distribution of $\mathrm{Al}$ and $\mathrm{Fe}$ near the $\mathrm{Fe}_{3} \mathrm{Al} / \mathrm{Q} 235$ interface is shown in figure 4 . The calculated values of concentration agree with the measured values. However, the calculated values cannot reflect fluctuations in element concentration. There was element segregation near the interface. The relation between the diffusion distance and square root of holding time near the $\mathrm{Fe}_{3} \mathrm{Al} / \mathrm{Q} 235$ interface at different temperatures is shown in figure 5 .

According to figure 5, the relation between the diffusion distance, $x$ and holding time, $t$, near the $\mathrm{Fe}_{3} \mathrm{Al} / \mathrm{Q} 235$ interface during the diffusion bonding satisfies following parabolic law

$$
x^{2}=K_{\mathrm{p}}\left(t-t_{0}\right)
$$

in which $x$, diffusion distance, $\mu \mathrm{m} ; K_{\mathrm{p}}$, diffusion rate, $\mu \mathrm{m}^{2} / \mathrm{s}$; $t$, holding time, $\mathrm{s} ; t_{0}$, latent time, $\mathrm{s}$.

Element diffusion rate is accelerated with increasing temperature, as seen from increase in the slope plots in figure 5 with temperature.

\subsection{Width of $\mathrm{Fe}_{3} \mathrm{Al} / \mathrm{Q235}$ interface transition zone}

There is an obvious interface transition zone near the $\mathrm{Fe}_{3} \mathrm{Al} / \mathrm{Q} 235$ interface. The width of this interface transition zone increases with holding time. The calculated diffusion coefficients of $\mathrm{Al}$ and $\mathrm{Fe}$ in the $\mathrm{Fe}_{3} \mathrm{Al} / \mathrm{Q} 235$ diffusion transition zone for different heating tempera-

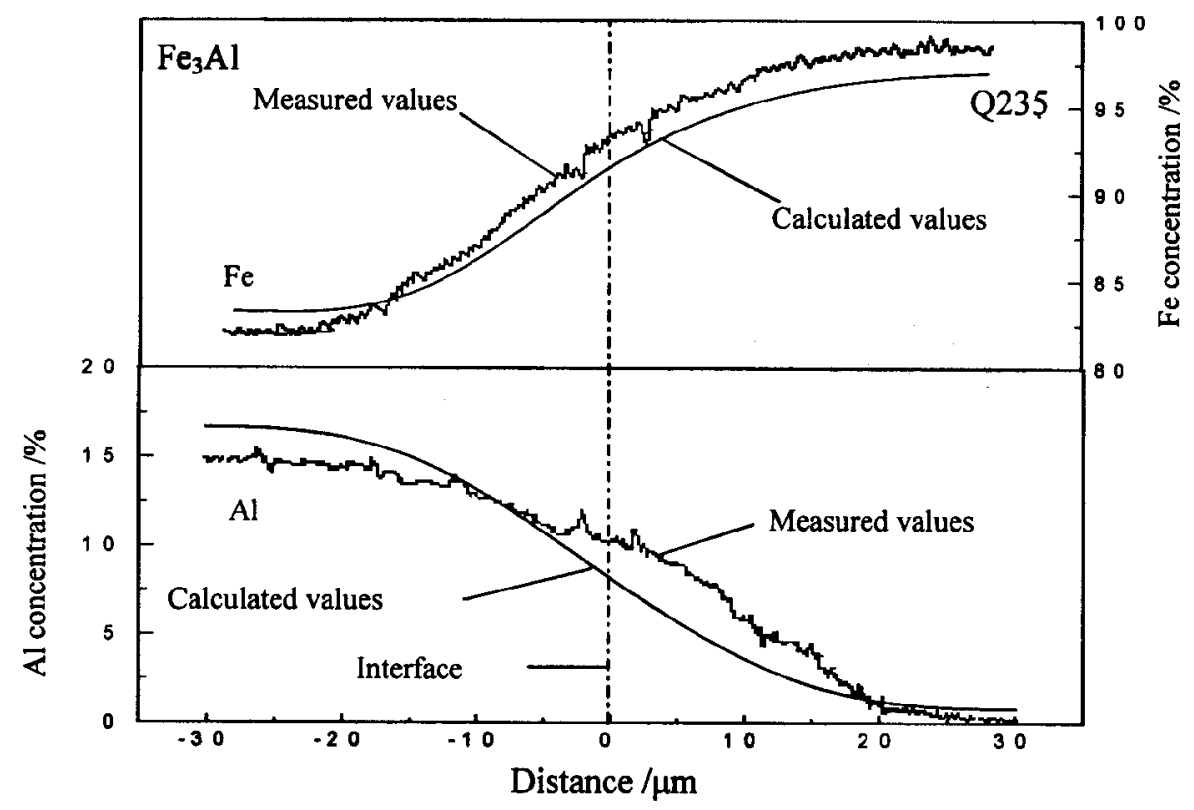

Figure 4. Element concentration distribution near the $\mathrm{Fe}_{3} \mathrm{Al} / \mathrm{Q} 235$ diffusion interface. 

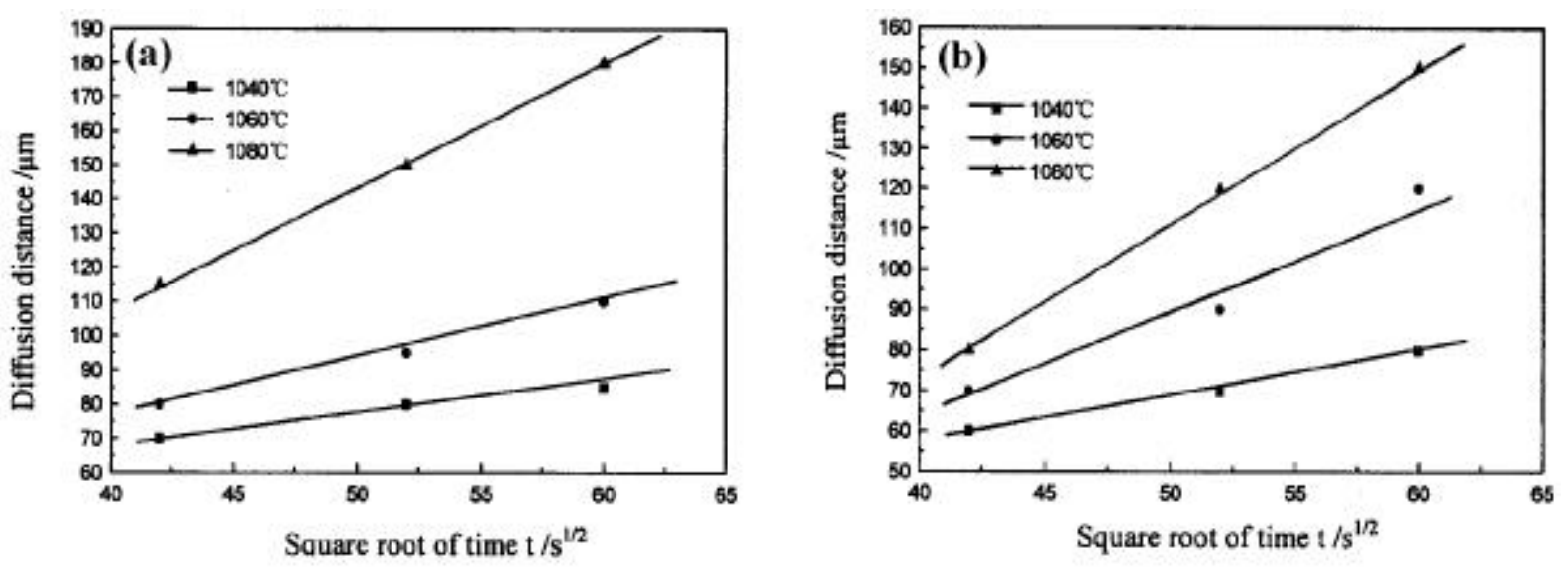

Figure 5. Relation between diffusion distance and square root of holding time near the $\mathrm{Fe}_{3} \mathrm{Al} / \mathrm{Q} 235$ interface: (a) $\mathrm{Al}$ and (b) Fe.

Table 3. Diffusion coefficients of $\mathrm{Al}$ and $\mathrm{Fe}$ in the $\mathrm{Fe}_{3} \mathrm{Al} / \mathrm{Q} 235$ diffusion transition zone.

\begin{tabular}{lcccc}
\hline Temperature $\left({ }^{\circ} \mathrm{C}\right)$ & & $1040(1313 \mathrm{~K})$ & $1060(1333 \mathrm{~K})$ & $1080(1353 \mathrm{~K})$ \\
\hline$D\left(\mu \mathrm{m}^{2} \cdot \mathrm{s}^{-1}\right)$ & $\mathrm{Al}$ & 0.51 & 1.91 & 3.80 \\
& $\mathrm{Fe}$ & 0.72 & 1.15 & 2.05 \\
$\ln \left(D \mu \mathrm{m}^{2} \cdot \mathrm{s}^{-1}\right)$ & $\mathrm{Al}$ & -0.67 & 0.69 & 1.29 \\
& $\mathrm{Fe}$ & -0.27 & $0 \cdot 14$ & 0.72 \\
\hline
\end{tabular}

tures are shown in table 3 . The variation of diffusion coefficients with temperature near the $\mathrm{Fe}_{3} \mathrm{Al} / \mathrm{Q} 235$ interface is shown in figure 6 .

From the plots in figure 6, the following are estimated: $Q_{\mathrm{Al}}=133 \mathrm{~kJ} / \mathrm{mol}, Q_{\mathrm{Fe}}=103 \cdot 9 \mathrm{~kJ} / \mathrm{mol}, D_{0(\mathrm{Al})}=10^{6} \times 23 \cdot 2 \mu \mathrm{m}^{2} / \mathrm{s}$, $D_{0(\mathrm{Fe})}=10^{6} \times 8.4 \mu \mathrm{m}^{2} / \mathrm{s}$.

For the same heating temperature, the diffusion coefficient in the interface transition zone is larger than that in $\mathrm{Fe}_{3} \mathrm{Al}$ alloy and Q235 steel, and increases rapidly with the heating temperature, which is favourable to element diffusion near the $\mathrm{Fe}_{3} \mathrm{Al} / \mathrm{Q} 235$ interface.

The width of the diffusion transition zone is represented using the maximum diffusion distance of Al element near the interface. The calculation indicated that the approximate width of $\mathrm{Fe}_{3} \mathrm{Al} / \mathrm{Q} 235$ diffusion transition is given by:

$$
x^{2}=4 \cdot 8 \times 10^{4} \exp \left(-\frac{133}{R T}\right)\left(t-t_{0}\right) .
$$

The measured values of the width of the diffusion transition zone, for different heating temperatures $(T=1020$ $\sim 1080^{\circ} \mathrm{C}$ ) and holding times $(t=30 \sim 80 \mathrm{~min})$, are shown in figure 7.

As noted earlier, the width of the diffusion transition zone, $x$, increases gradually with increasing heating temperature, $T$ and holding time, $t$. However, the increase is small beyond $60 \mathrm{~min}$. The calculated value $(x=30 \cdot 1 \mu \mathrm{m})$

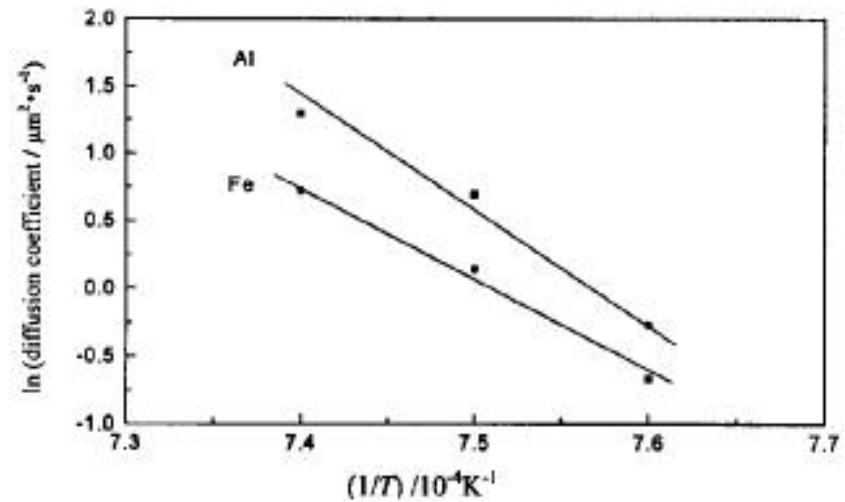

Figure 6. Relation of diffusion coefficients and temperature near the $\mathrm{Fe}_{3} \mathrm{Al} / \mathrm{Q} 235$ diffusion interface.

of the width of $\mathrm{Fe}_{3} \mathrm{Al} / \mathrm{Q} 235$ diffusion transition zone from (6) is compared with the EPMA measured value $(x=28.6 \mu \mathrm{m})$ under the condition of $1060^{\circ} \mathrm{C} \times 60 \mathrm{~min}$ diffusion bonding. There is a good agreement between the two values.

Diffusion transition zone with a certain width is required for best performance of the $\mathrm{Fe}_{3} \mathrm{Al} / \mathrm{Q} 235$ joints. There exists a certain latent time, $t_{0}$, for the formation of $\mathrm{Fe}_{3} \mathrm{Al} / \mathrm{Q} 235$ diffusion transition zone. This time, $t_{0}$, becomes shorter with increasing heating temperature, $T$. Therefore, holding time, $t$, should be controlled properly 

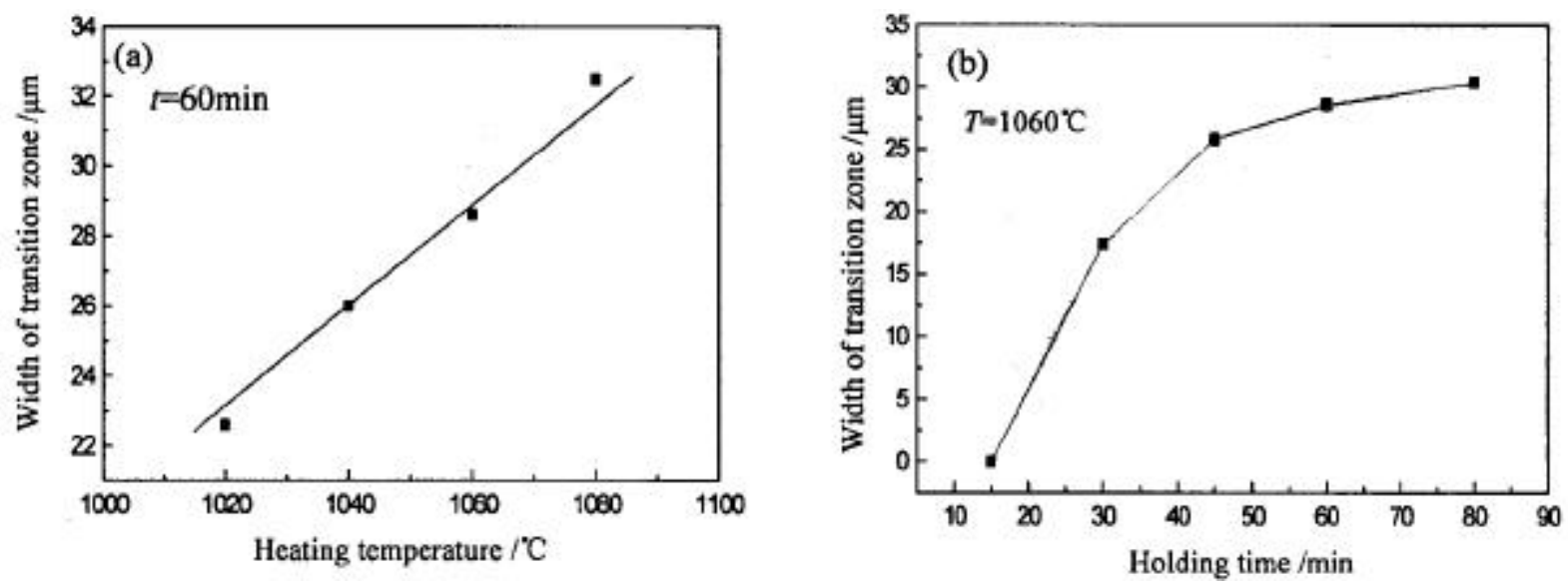

Figure 7. Effect of (a) heating temperature and (b) holding time on width of the diffusion transition zone.

at a given heating temperature, $T$, to obtain the desired optimum width of the transition zone.

\section{Conclusions}

(I) The calculated values of concentration of $\mathrm{Al}, \mathrm{Fe}$ near the $\mathrm{Fe}_{3} \mathrm{Al} / \mathrm{Q} 235$ interface conform to the experimental values obtained by EPMA. With increasing heating temperature, $T$ and holding time, $t$, diffusion distance of the elements in the diffusion transition zone for $\mathrm{Fe}_{3} \mathrm{Al} / \mathrm{Q} 235$ dissimilar materials increases.

(II) Diffusion coefficient of $\mathrm{Fe}$ and $\mathrm{Al}$ in the $\mathrm{Fe}_{3} \mathrm{Al} / \mathrm{Q} 235$ interface transition zone is larger than that in $\mathrm{Fe}_{3} \mathrm{Al}$ and Q235 base materials at the same temperature. The microstructure near the $\mathrm{Fe}_{3} \mathrm{Al} / \mathrm{Q} 235$ interface is favourable for diffusion.

(III) There exists a latent time, $t_{0}$, for the formation of diffusion transition zone near the $\mathrm{Fe}_{3} \mathrm{Al} / \mathrm{Q} 235$ interface.
The relation between the width of transition zone, $x$, and holding time, $t$, follows a parabolic growth law.

(IV) Activation energy for diffusion of $\mathrm{Fe}$ and $\mathrm{Al}$ has been estimated.

\section{Acknowledgements}

This project was supported by the National Natural Science Foundation of China (50375088) and Shandong Province Natural Science Foundation (Y2003F05).

\section{References}

David S A et al 1989 Weld. J. 68372

David S A et al 1993 Weld. J. 72201

Derby B et al 1982 Metal Sci. 1649

He Peng et al 2002 Trans. China Weld. Inst. 2380 (in Chinese) Huang Jihua 1996 Diffusion in metals and alloys (Beijing: Metallurgical Industry Press) p. 33

Mckamey C G et al 1991 J. Mater. Res. 61779 